www.jmscr.igmpublication.org

Impact Factor (SJIF): 6.379

Index Copernicus Value: 71.58

ISSN (e)-2347-176x ISSN (p) 2455-0450

crossrefDOI: https://dx.doi.org/10.18535/jmscr/v6i7.117

Journal Of Medical Science And Clinical Research

\title{
Prevalence of Hypertension among 20-40 years in rural population Veerapandi
}

\author{
Author
}

\section{Dr M.Thiruvenkadam.M.D}

Community Medicine, Assistant professor, Govt Theni Govt Medical College

\begin{abstract}
Background: Hypertension is the commonest cardiovascular disorder and a major risk factor for other cardiovascular disorders, stroke and myocardial infarction and its complications are increasing disproportionately in developing countries as they undergo demographic transition. An epidemiological shift in the prevalence of hypertension in developing countries as compared to developed countries has been observed.

Objectives: 1) To find out the prevalence of hypertension among the age group of 20 - 40 years, in rural population, veerapandi, Theni dt. 2) To find out the association between hypertension and selected risk factors (age, sex, exercise, obesity)

Methodology: A community based cross sectional study was done from January 2017 - December 2017 in rural Population of veerapandi, 600 participants aged 20-40 years were enrolled into the study. Each study subject was interviewed and examined for raised blood pressure, data on risk factors including exercise, obesity were also collected. Data were analysed by using SPSS version 20.0.

Results: The overall prevalence of hypertension was $20.8 \% .6 \%$ were pre hypertensive. Out of the study participants, $55.2 \%$ were females and $44.8 \%$ were males $22.3 \%$ were obese and $36.7 \%$ were doing exercise. The selected risk factors like physical activity and obesity were found to be significantly associated with hypertension.

Conclusion: Among the risk factors of hypertension, lack of exercise and obesity were found to be more associated with hypertension in this group. Therefore health intervention measures are warranted emphasizing on modifiable risk factors such as exercise and obesity to prevent hypertension in younger population.

Keywords: cross-sectional study, hypertension, prevalence, risk factors.
\end{abstract}

\section{Introduction}

Hypertension is the commonest cardiovascular disorder and one of the major risk factors for cardiovascular mortality which accounts for 20$50 \%$ of all deaths. ${ }^{1}$ Globally, the overall prevalence of hypertension or raised blood pressure in adults aged 25 and above was about $40 \%$ in $2008 .^{2}$ It affects nearly $26 \%$ of the population worldwide. ${ }^{3}$ Hypertension exhibits an ice-berg phenomenon. ${ }^{1}$ Worldwide raised blood pressure is estimated to cause 7.5 million deaths and about $12.8 \%$ of the total of all annual deaths. It accounts for $3.7 \%$ of total DALYs. ${ }^{2}$ Prevalence rates of hypertension in urban Indian population to be $29-45 \%$ in men and $25-38 \%$ in women. ${ }^{4}$ 
A study by Amrinder Singh et al in 2014, reported the prevalence of $10.7 \%$ and $19.8 \%$ in the age group of 20-29years and 30-39 years respectively. A meta-analysis of prevalence studies on hypertension in India from January 2000 to July 2012 revealed high prevalence of hypertension in urban (40.8\%)as well as rural population $(17.9 \%) .^{2}$ It is estimated that by 2020 , Cardio vascular diseases will be largest cause of mortality and morbidity in India. ${ }^{4}$ Hypertension is a major risk factor for cardiovascular disorders, stroke and myocardial infarction and its complications are increasing disproportionately in developing countries as they undergo demographic transition. ${ }^{4}$ The risk factor for hypertension are basically of two types - non-modifiable (age, sex, genetic factors, ethnicity) and modifiable (obesity, salt intake, saturated fat, dietary fibre, alcohol, physical activity). ${ }^{1}$

An epidemiological shift in the prevalence of hypertension in developing countries as compared to developed countries has been observed. ${ }^{5}$ This study was done to find out the prevalence of hypertension among 20-40 years age group in urban population, Chidambaram and the association between hypertension and selected risk factors like age, sex, physical activity and obesity.

\section{Methodology}

This community based cross sectional study was carried out among the age group of 20 - 40 years in rural population, veerapandi, Theni dt between January 2017 to December 2017. Before the actual study, a pilot study was conducted between January 2017 to March 2017, and the prevalence was found to be $14 \%$. Relative precision as $20 \%$ the sample size was calculated using the following formula

$\mathrm{n}=\mathrm{Z}^{2} * \mathrm{p}(1-\mathrm{p}) /(£ \mathrm{p})^{2}$

The sample size obtained was 589. However 600 subjects between 20-40 years has been selected for the study.

Out of the wards in rural veerapandi, one ward()was selected randomly. Within the ward 5 streets namely the street, st, st, st, st., were covered under the study by house to house visit. The persons in each house, who were in the age group of 20-40 years and had given consent were taken as study participants. In the study, persons who were unavailable even after 2 visits and those out of town were excluded. The basic demographic details and data on smoking, alcohol consumption and exercise were collected using a proforma. Their blood pressure and anthropometry were recorded using the following methods.

Blood Pressure was recorded by auscultatory method. Every individual was placed in a comfortable seating position with back supported well and uncrossed legs. The arm was supported at the level of right atrium i.e., midpoint of sternum. After the palpation of brachial artery in the anticubital fossa the chest piece of stethoscope was placed on. The cuff was placed in such a manner that the lower end was 2 to $3 \mathrm{~cm}$ above anticubital fossa to allow room for placement of chest piece. The cuff was inflated to $20-30 \mathrm{~mm}$ of $\mathrm{Hg}$ above the pressure at which the radial pulse disappeared to palpation. The cuff was gradually deflated at a constant rate of $2-3 \mathrm{~mm}$ of $\mathrm{Hg}$ per second. Systolic blood pressure was noted as the reading at which the first korotkoff sound heard and the diastolic blood pressure was noted at the point at which the sound disappeared. As per Joint National Commitee (JNC) VII criteria, the subjects having systolic blood pressure = $140 \mathrm{mmHg}$ or $<160 \mathrm{mmHg}$ and / or diastolic blood pressure $=90 \mathrm{mmHg}$ or $<100 \mathrm{mmHg}$ were categorized as of mild grade hypertension. Those having systolic blood pressure $=160 \mathrm{mmHg}$ and $180 \mathrm{mmHg}$ and / or diastolic blood pressure $=100$ $\mathrm{mmHg}$ but $<110 \mathrm{mmHg}$ were categorized as of moderate grade of hypertension and those having systolic blood pressure $\geq 180 \mathrm{mmHg}$ and diastolic blood pressure $\geq 110 \mathrm{mmHg}$ were categorized as of severe grade of hypertension. ${ }^{6}$

Height was measured without shoes, to the nearest $0.5 \mathrm{~cm}$ with participant standing erect against the wall with heels together and touching the wall, and head held in upright position. Weight was 
measured with minimum cloths and no footwear on a standardized weighing machine marked from 0 to $130 \mathrm{~kg}$ and was recorded to the nearest 0.5 $\mathrm{kg}$. Body Mass Index (BMI) was calculated using the formula BMI $=$ Weight $(\mathrm{kg}) / \operatorname{Height}^{2}(\mathrm{~m})$. Subjects were classified according to BMI $<=25$ as normal $>30$ obese. The same inch tape and Bathroom weighing machine was used by a single person throughout the study.

Physical activity is defined as any bodily movement produced by contraction of skeletal muscles that increases energy expenditure above resting levels and comprises routine daily tasks such as commuting, occupational tasks or household activities as well as purposeful health enhancing movements ${ }^{7}$. Taking routine sleep as 8 hours, the remaining 16 hours taken and with the help of a questionnaire the duration of no, mild to moderate and vigorous physical activity were obtained from the study participants.

\section{Results}

Out of the 600 study participants, most of them (38.2\%) belong to the age group of 35-40 years followed by 30-34 years (22.2\%) and 25-29 years (21.8\%). $55.2 \%$ of the study participants were females and $44.8 \%$ were males (Table: 1 ).

The prevalence of hypertension among 20-40 years age group was found to be $20.8 \%$ (Figure:1). Among hypertensives, majority of the study participants $64.8 \% \quad(n=81)$ were in Stage 1(Table:2). $22.3 \%$ of the study participants were obese and $36.8 \%(n=221)$ were not doing exercise (Table 3).

Obesity was found to be significantly associated with hypertension. When compared to non-obese individuals, obese individuals have 2 times risk of getting hypertension. The study participants who were doing vigorous physical activity for 2 or more hours were having $50 \%$ less risk of getting hypertension. (table 4).

Table no: 1 Age and sex wise distribution of the study participants

\begin{tabular}{|c|c|c|c|c|c|c|}
\hline \multirow{2}{*}{ Age } & \multicolumn{2}{|c|}{ Male } & \multicolumn{2}{c|}{ Female } & \multicolumn{2}{c|}{ Total } \\
\cline { 2 - 7 } & $\mathbf{N}$ & $\mathbf{\%}$ & $\mathbf{N}$ & $\mathbf{\%}$ & $\mathbf{N}$ & \% \\
\hline $20-24$ & 51 & 19 & 56 & 16.9 & 107 & 17.8 \\
\hline $25-29$ & 53 & 19.7 & 78 & 23.6 & 131 & 21.8 \\
\hline $30-34$ & 62 & 23 & 71 & 21.5 & 133 & 22.2 \\
\hline $35-40$ & 103 & 38.3 & 126 & 38.1 & 229 & 38.2 \\
\hline Total & $\mathbf{2 6 9}$ & $\mathbf{4 4 . 8}$ & $\mathbf{3 3 1}$ & $\mathbf{5 5 . 2}$ & $\mathbf{6 0 0}$ & $\mathbf{1 0 0}$ \\
\hline
\end{tabular}

Majority of study population are in the age group of 35-40 yrs followed by 30-34 yrs and $25-29$ yrs.

Figure: 1 Percentage of distribution of hypertensives and non hypertensives

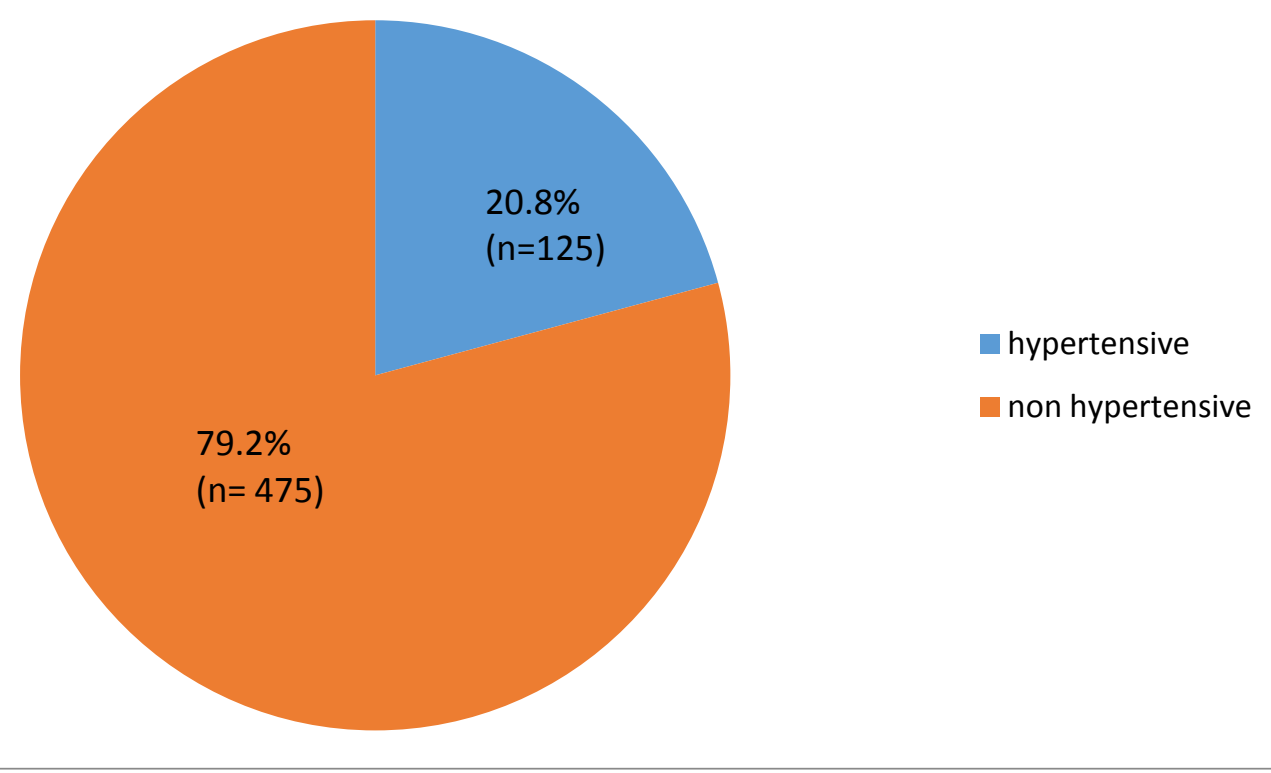


Table 2 Distribution of hypertension as per JNC VII criteria

\begin{tabular}{|l|c|c|c|c|c|c|}
\hline \multirow{2}{*}{} & \multicolumn{2}{|c|}{ Male } & \multicolumn{2}{c|}{ Female } & \multicolumn{2}{c|}{ Total } \\
\cline { 2 - 7 } & $\mathrm{N}$ & $\%$ & $\mathrm{~N}$ & $\%$ & $\mathrm{~N}$ & $\%$ \\
\hline Stage 1 & 43 & 53.1 & 38 & 46.9 & 81 & 64.8 \\
\hline Stage 2 & 17 & 41.5 & 24 & 58.5 & 41 & 32.8 \\
\hline Stage 3 & 2 & 66.7 & 1 & 33.3 & 3 & 2.4 \\
\hline Total & 62 & 49.6 & 63 & 50.4 & 125 & 100 \\
\hline
\end{tabular}

Among the hypertensives, majority of the study participants were in Stage 1.

Table 3 Distribution of risk factors among study participants

\begin{tabular}{|c|c|c|c|c|c|c|c|}
\hline \multirow{2}{*}{\multicolumn{2}{|c|}{ Risk factor }} & \multicolumn{2}{|c|}{ Male } & \multicolumn{2}{|c|}{ Female } & \multicolumn{2}{|c|}{ Total } \\
\hline & & $\mathrm{N}$ & $\%$ & $\mathrm{~N}$ & $\%$ & $\mathrm{~N}$ & $\%$ \\
\hline \multicolumn{2}{|l|}{ Sex } & 269 & 44.8 & 331 & 55.2 & 600 & 100 \\
\hline \multirow[t]{2}{*}{ Obesity } & Yes & 78 & 58.2 & 56 & 41.8 & 134 & 22.3 \\
\hline & No & 187 & 40.1 & 279 & 59.9 & 466 & 77.7 \\
\hline \multirow{2}{*}{$\begin{array}{l}\text { Vigorous } \\
\text { Physical activity }\end{array}$} & $>=2$ & 86 & 18.5 & 378 & 81.5 & 464 & 77.3 \\
\hline & $<2$ & 39 & 28.7 & 97 & 71.3 & 136 & 22.7 \\
\hline
\end{tabular}

Table: 4 Relationship of risk factors with hypertension

\begin{tabular}{|c|c|c|c|c|c|c|c|c|c|}
\hline \multirow{2}{*}{\multicolumn{2}{|c|}{ Risk factor }} & \multicolumn{2}{|c|}{ Hypertensive } & \multicolumn{2}{|c|}{ Non-hypertensive } & \multirow[t]{2}{*}{$\mathbf{X}^{2}$} & \multirow[t]{2}{*}{ P value } & \multirow[t]{2}{*}{$\overline{\text { OR }}$} & \multirow[t]{2}{*}{ CI } \\
\hline & & $\mathbf{N}$ & $\%$ & $\mathbf{N}$ & $\%$ & & & & \\
\hline \multirow[t]{2}{*}{ Sex } & $\mathrm{M}$ & 62 & 23 & 207 & 77 & \multirow[t]{2}{*}{1.5} & \multirow[t]{2}{*}{0.22} & \multirow[t]{2}{*}{1.3} & \multirow[t]{2}{*}{$0.859-1.891$} \\
\hline & $\mathrm{F}$ & 63 & 19 & 268 & 81 & & & & \\
\hline \multirow[t]{2}{*}{ Obesity } & Yes & 78 & 58.2 & 56 & 41.8 & \multirow[t]{2}{*}{13.7} & \multirow[t]{2}{*}{$<0.05$} & \multirow[t]{2}{*}{2.07} & \multirow[t]{2}{*}{$0.456-0.865$} \\
\hline & No & 187 & 40.1 & 279 & 59.9 & & & & \\
\hline \multirow{2}{*}{$\begin{array}{l}\text { Vigorous } \\
\text { Physical activity }\end{array}$} & $>=2$ & 86 & 18.5 & 378 & 81.5 & \multirow[t]{2}{*}{6.5} & \multirow[t]{2}{*}{0.01} & \multirow[t]{2}{*}{0.56} & \multirow[t]{2}{*}{$0.365-0.878$} \\
\hline & $<2$ & 39 & 28.7 & 97 & 71.3 & & & & \\
\hline
\end{tabular}

\section{Discussion}

\section{Prevalence of hypertension}

The prevalence for our study between the age group 20-40 years was $20.8 \%$, which was similar to that of a study done by Q Wei et al in 2015 in China which found a prevalence of $19.3 \%$ among the age group of 18-44 years ${ }^{8}$.Anotherstudy by Sanjeet Panesar et al in 2013 in Delhi stated that the prevalence of hypertension in the age group of $20-29$ and $30-39$ years was $5.7 \%$ and $19.3 \%$ respectively ${ }^{9}$. Similar study from Senegal by Soulemane Pessinaba et al in 2013 reported a prevalence of $23 \%$ among the age group 25-34 years in Sub-Saharan Africa ${ }^{10}$. Manimunda SP et al 2011 stated that the prevalence of hypertension among age groups of more than 20 years to be $20.7 \%$ in Andaman and Nicobar Islands ${ }^{11}$.

\section{Age and hypertension}

Our finding suggested that the risk of hypertension increases significantly with age which was similar to a study by Basu and Millet in 2013in which stated that the risk of hypertension increases significantly with age with odds ratio of 4.6 with confidence interval $3.0-$ $7.1^{12}$. Similar results were found in study done by Soulemane Pessinaba et al in 2013 which showed that the hypertension was significantly associated with age $(p$ value $=0.001)$ in Senegal ${ }^{10}$.

\section{Sex and hypertension}

Our study finding states that male and female are equally prone to hypertension. A meta-analysis study SAARC $2014^{13}$ and NNMB rural report 2006 stated that the prevalence of hypertension in male is more than that of females ${ }^{14}$. In contrast, Studies by Kusuma YS et al $2004^{15}$ and Tiwari et al 2008 reported an increased prevalence among females than that in males ${ }^{14}$. NNMB tribal report 2009 in Tamilnadu stated that the prevalence of hypertension is almost equal in both males and females aged more than 20 years, which was $18.4 \%$ and $18.2 \%$ respectively ${ }^{14}$.

\section{Obesity and hypertension}

In our study obese persons were 5.7 times at higher risk of getting hypertension than a nonobese person. This is similar to Basu and Millet study where obesity was significantly correlated 
with hypertension with odds ratio of 3.7 and confidence interval of 2.1-6.8 ${ }^{12}$. Another study from Kabul, Afghanistan in 2014 done by Khwaja Mir Islam Saeed et al stated that the obese persons were 2.08 times greater risk of hypertension than non-obese person with $\mathrm{p}$ value $<0.001$; confidence interval $1.50-2.89^{16}$. Similar study by Soulemane Pessinaba et al in 2013 in Senegal revealed that obesity was significantly associated with hypertension with $\mathrm{p}$ value $<0.001^{10}$.

\section{Physical activity and hypertension}

In our study, the study participants who were doing vigorous physical activity or 2 hours or more were having $50 \%$ less risk of getting hypertension as compared to those who do not do exercises. However this difference is not statistically significant. Other studies done by David R. Basette Jr in 2002 in US stated that the hypertension prevalence was significantly less in most active group compared with their sedentary peer with $\mathrm{OR}=0.73$; confidence interval: 0.59 to $0.9^{17}$.A study done by S.S. Reddy et al in 2005 in adults aged 20 to 60 years revealed that significantly higher proportion of hypertension $(15.8 \%)$ was associated with lack of physical activity with $\mathrm{OR}=2.4$ (Coinfidence Interval $=2.0$ $-2.8)^{18}$. A study done by Soulemane Pessinaba et al in 2013 in Senegal revealed that physical inactivity is significantly associated with hypertension with $\mathrm{p}$ value $<0.001^{10}$.

\section{Conclusion}

The present study found that the prevalence of $20.8 \%$ hypertension among 20-40 years age group. Among the risk factors of hypertension, lack of exercise and obesity were found to be more associated with hypertension in this group. Therefore health intervention measures are warranted emphasizing on modifiable risk factors such as exercise and obesity to prevent hypertension in younger population.

\section{References}

1. Park. Park Text book of Preventive and Social Medicine, $24^{\text {th }}$ edition,372-377.

2. Tanu Midha, Bhola Nath, Ranjeeta Kumari, Yashwant Kumar Rao, Umeshwar Pandey: Prevalence of hypertension in India: A meta-analysis. World J Meta-Anal $2013,1(2): 83-89$.

3. S.Yadav, R.Boddula, G. Genitta, V. Bhatia, B.Bansal, S.Kongara et al. Prevalence \& risk factors of prehypertension $\&$ hypertension in an affluent north Indian north population. Indian $\mathbf{J}$ Med Res 128 2008;712 - 720

4. Amrindar Singh, Shweta Shenoy, Jaspal Singh Sandhu: Prevalence of Hypertension and its Risk actors among Urban Sikh Population of Amritsar IJSR 2014 vol3 issue $3,827-832$.

5. Chataut J, Adhikari RK, Sinha NP, Prevalence and Risk Factors for Hypertension in Adults Living in Central Development Region of Nepal; Kathmandu Univ Med J 2011;33(1)13-8.

6. Izharul Hasan, Mahboob Ali, Mustaq Hussain: Prevalence of hypertension among population of Sultanpur Kunhari and its surrounding area, Haridwar , Uttarkand, India. IRJP 2012,3(3)310-314

7. Keith M. Diaz, Daichi Shimbo : Physical Activity and the Prevention of Hypertension CurrHypertens Rep. 2013 Dec; 15(6): 659-668.

8. Q Wei, J Sun, J Huang, H-Y Zhou, Y-M Ding, Y-C Tao et al. Prevalence of hypertension and associated risk factors in Dehui City of Jilin Province in China. Journal of Human Hypertension .2015; 29: 64-68.

9. Sanjeet Panesar, Sanjay Chaturvedi, N.K. Saini, Rajnish Avasthi, Abhishek Singh. Prevalence and predictors of hypertension among residents aged $20-59$ years of a slum - resettlement colony in Delhi, India. 
WHO South - East Asia Journal of Public Health. 2013;2(2).

10. Soulemane Pessinaba, AlassaneMbaye, Grace-a-dieu Yabeta, Adamakane, Cheikh Tidiane Ndao, Mouhamadou Bamba Ndiaye et al. Prevalence and determinants of hypertension and associated cardiovascular risk factors: data from a population-based, cross-sectional survey in Saint Louis, Senegal. Cardiovascular Journal of Africa • 2013; 24( 5):180-183.

11. Manimunda SP, Sugunan AP, Benegal V, Balakrishna N, Rao MV, et al. (2011) Association of hypertension with risk factors \& hypertension related behaviour among the aboriginal Nicobarese tribe living in Car Nicobar Island, India.Indian J Med Res 133: 287-293.

12. Sanjay Basu, Christopher Millett. Social Epidemiology of Hypertension in MiddleIncome Countries Determinants of Prevalence, Diagnosis, Treatment, and Control in the WHO SAGE Study. Hypertension. 2013;62:18-26.

13. Dinesh Neupane, Craig S. McLachlan, Rajan Sharma, Bishal Gyawali, Vishnu Khanal, Shiva Raj Mishra, et al. Prevalence of Hypertension in Member Countries of South Asian Association for Regional Cooperation (SAARC): Systematic Review and Meta-Analysis. Medicine • 2014; 93(13):1-10.

14. S. A. Rizwan, Rakesh Kumar, Arvind Kumar Singh, Y. S. Kusuma, Kapil Yadav, Chandrakant, Pandav. Prevalence of Hypertension in Indian Tribes: A Systematic Review and Meta-Analysis of Observational Studies. PLOS ONE. 2014;9(5):1-10.

15. Kusuma YS, Babu BV, Naidu JM (2004) Prevalence of hypertension in some crosscultural populations of Visakhapatnam district, south India. Ethn Dis14:250-259.
16. Khwaja Mir Islam Saeed, Mohammad Hafez Rasooly and Nick JW Brown. Prevalence and predictors of adult hypertension in Kabul, Afghanistan. BMC Public Health. 2014; 14(386):1-7.

17. David R Bassett Jr, Eugene C Fitzhugh, Carlos J Crespo, George A King, James E McLaughlin, Physical Activity and Ethnic Differences in Hypertension Prevalence in the United States; Volume 34, Issue 2, 2002 179-186.

18. S.S. Reddy, G.R. Prabhu .Prevalence and Risk Factors of Hypertension in Adults in an Urban Slum, Tirupati, A.P. Indian Journal of Community Medicine Vol. 30, No. 3, 2005. 